\title{
EDITORIAL
}

\section{Rodriguésia: 80 years disseminating Botanical Science}

The first volume of Rodriguésia was published during the winter of 1935 , supported by the Instituto de Pesquisas Jardim Botânico do Rio de Janeiro (Fig. 1). This year our journal celebrates 80 years of existence as the oldest Brazilian journal to publish articles exclusively in Plant Biology. Since its inception, over 1000 manuscripts have been published, authored by researchers from diverse Brazilian states and many countries in South and Central America, North America, Europe and Asia.

Articles are reviewed by an editorial board composed of proeminent international researchers, some of them from American and European institutions. According to the base SCImago, the $\mathrm{h}$ index of Rodriguésia, an indicator of periodic citation, estimated in a period between 2011 and 2014, is seven. According to Scholar Google, the h5 (the h index calculated using only articles published in the past 5 years) has reached 8 while the h5 median (which is the average number of articles included in h5) is now at 16 .

Between 2011 and 2014, a considerable increase was recorded in relation to various ratings obtained by the journal, as seen in Table 1. This improvement reflects the position of Rodriguésia that allies its strong tradition to a continuously evolving attitude looking towards the future. Strong assets that contribute to this journal's posture are free access to all papers and the fact that this journal does not belong to any society, requiring no annual fee or any other type of membership or payment from publishing authors.

Recently its website has been moved to a new electronic submission platform using the ScholarOne system by Thomson Reuters. The entire contents of the journal, from 1935 onwards, were digitalised, stored and made available on its website. Since 2012 Rodriguésia has been indexed in Scielo and SCImago bases, ensuring more visibility for the journal, with increasing number of article citations. Another important achievement is the availability of the entire digitised collection via the JSTOR base. Future aims include an increase on the number or articles submitted for publication, as well as of the articles in English, the reduction of the time elapsed between submission and acceptance of papers, and finally to index Rodriguésia in the Core Collection of the Web of Science, by Thomson Reuters, in order to receive a JCR index, a measure widely used to evaluate journals in the scientific arena.

The journal has a policy of not restricting the number of pages in order to encourage valuable floristic studies or taxonomic revisions that are often denied space in many modernized journals.

Rodriguésia has welcomed the publication of special volumes with themed articles to increase visibility of publications. Starting in 2005, a special issue dedicated to the Araceae family with the contribution of Brazilian and foreign scientists. During the same year the journal celebrated its 70th anniversary with a special volume dedicated to contributions towards the Flora of the Reserva Ducke, the first flora of the Brazilian Amazon Rainforest to be published after the Flora brasilliensis (1840-1906). The Flora of the Reserva Ducke continued to be published in two subsequent volumes in 2006 and 2007. A special volume on Fabaceae was published in 2007 and the overwhelming response from scientists meant that a second volume dedicated to this plant family had to be prepared in 2008. A special volume dedicated the centre of diversity of Cabo Frio in Rio 
de Janeiro followed and, in 2010 , two volumes covered relevant updates for the Flora of Brazil to accompany taxonomic decisions prompted by the Brazilian Plant and Fungi List. A volume on aquatic plants was organized in 2011 . In 2012 papers in taxonomy were organized aroudn a tribute to the birth centenary of Dr Graziela Maciel Barroso, a leading researcher at the Rio de Janeiro Botanical Garden of international renown for her contribution to the study of Botany. Collections of articles addressing the diversity of the Northeastern Brazil flora, focusing on the flora of Ceará and of some localities of Pernambuco were published in 2013, 2014 and 2015.

The second volume of 2015 was dedicated to Dr Ana Maria Giulietti-Harley, a leading botanical researcher in Brazilian Monocotyledoneae who supervised many of Brazil's active taxonomists. Most of the articles in this volume were published in English and feature authors from all over the world.

The third volume of 2015 that I present here comprises 21 regular flow articles featuring contributions encompassing new species, regional floras, vegetation classification, palinology and reproductive studies, effects of mining on plant diversity and studies of the diversity of the Colombian Chocó, a peculiar region with high diversity.

The last volume of 2015 commemorates 80 years of Rodriguésia and will be dedicated to the World Flora online project, including current data on the progress of this important and audacious project. We will have insights on different countries and regions floristic diversity, with contributions from Bolivia, Cameroon, Malaysia, Southern Cone and North America, collected as a framework to present the advancement of the knowledge five years after the publication of the Brazilian List of Plant and Fungi (Forzza et al. 2010). It is expected that all this effort will ensure a very positive balance for the year of 2015 taking into account the high quality and the breadth these articles content.

Recent changes in the context and availability of specialized journals, together with increasing pressure to publish with higher impact levels has given the lead to journals printed by renowned publishers and whose content is available only upon payment. As a consequence, many scientific journals have joined powerful publishing houses, ensuring that their indexes, such as Journal Citation Reports (JCR) have increased steadily. Rodriguésia is of the principle that free access to its contents is the politically correct way to disseminate science that is largely, and especially in Brazil, carried out using public funds. Unfortunately CAPES, the Brazilian Education Ministry agency that evaluates our Post-graduate Programmes (from here onwards PGPs), evaluates journals using the metric system that favours journals from large publishing houses. A large proportion of Brazil's publication output are generated by students from the various PGPs that need to produce publications of higher impact in order to obtain jobs in the future, therefore their papers are submitted to paid, non open-access journals. The devaluation of freeaccess journals reaches extremes where the SciELO platform is compared to a publication slum, or 'favela' (see http://scholarlyoa.com/2015/07/30/is-scieloa-publication-favela/), furthering the deterioriation of the situation on the eyes of the evaluators of our PGPs, who systematically devalue publications made outside the scheme of the large publishing houses.

On the other hand, growing reach of visibility provided by the internet, partnered with the quality and usefulness of our publications is helping our journal to overtake the obstacles imposed by a system that appears to be fostering the control of scientific dissemination through financial means. Rodriguésia has as its main objectives to expand its capacity to disseminate scientific research and to contribute to the development of Plant Sciences in Brazil and globally through free access of its contents.

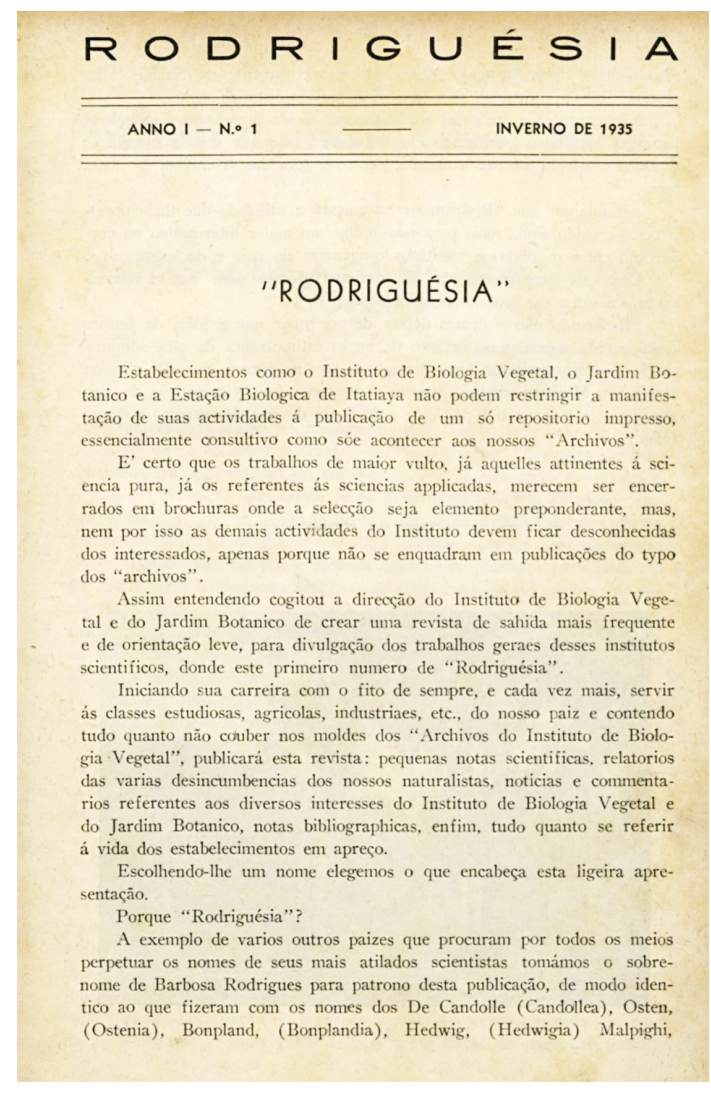

Figure 1 - Cover of the first volume of Rodriguesia published during the Spring of 1935. 
Table 1 - Indicators of the journal Rodriguésia, ISSN: 03706583, 21757860 in the area of Agricultural and Biological Sciences.

\begin{tabular}{lccc}
\hline Indicators & 2012 & 2013 & 2014 \\
\hline SJR* & 0,182 & 0,312 & 0,364 \\
Total Documents & 81 & 64 & 67 \\
Total Docs. (3years) & 66 & 147 & 211 \\
Total References & 3.707 & 2.569 & 2.657 \\
Total Cites (3years) & 31 & 92 & 151 \\
Self Cites (3years) & 11 & 31 & 44 \\
Citable Docs. (3years) & 65 & 145 & 209 \\
Cites / Doc. (4years) & 0,48 & 0,63 & 0,72 \\
Cites / Doc. (3years) & 0,48 & 0,63 & 0,72 \\
Cites / Doc. (2years)** & 0,48 & 0,63 & 0,67 \\
References / Doc. & 45,77 & 40,14 & 39,66 \\
Cited Docs. & 18 & 57 & 88 \\
Uncited Docs. & 48 & 90 & 123 \\
\% International Collaboration & 7,41 & 9,38 & 16,42 \\
\hline
\end{tabular}

* SJR measures the influence of the average article in a journal. It shows how central to the global scientific discussion an average article of the journal is. ${ }^{*}$ Cites per Document $(2 \mathrm{y})$, and so on, show the impact of an average article published in the journal calculated using the same formula of journal impact factor. The definitions are based on SCImago information found at http://www.scimagojr. com/journalsearch.php?q=21757860\&tip=iss\&exact=yes\%3E.

Vidal de Freitas Mansano \& Karen De Toni

Botanical Garden Research Institute of Rio de Janeiro

Rio de Janeiro - RJ, Brazil 